\title{
A cDNA Clone, Encoding a New NBS-LRR Protein, Expressed in Immature Anthers and Leaves of Rice Plant
}

\author{
Kinya TORIYAMA and Yoshitaka OHHASHI \\ Laboratory of Plant Breeding and Genetics, Graduate School of Agricultural Science \\ Tohoku University, Sendai 981-8555, Japan E-mail:
}

Received 26 April 1999; accepted 30 June 1999

\begin{abstract}
Differential display of immature anther cDNA was carried out between restorer and maintainer lines of $[m s-b o]$ cytoplasmic male sterile rice. One clone (DD2-3) was identified to be specific to restorer line. However DD2-3 was mapped on the chromosome 11 and was not linked to fertility - restorer gene, $R f-1$. Full length cDNA of DD2-3 was obtained and the predicted amino acid sequence contains leucine zipper structure, followed by nucleotide binding site (NBS) and leucine rich repeats (LRR). These structures are characteristics of the NBS-LRR class of plant disease-resistant genes. The transcripts of DD2-3 were detected in the anthers at the microspore stage and leaves.
\end{abstract}

The nucleotide sequence data reported appear in the DDBJ, EMBL and GenBank nucleotide sequence databases under accession number $\mathrm{AB} 017914$.

Differential display of immature anther cDNA was carried out between restorer and maintainer lines of $[m s-b o]$ cytoplasmic male sterile rice (Oryza sativa L.) in an attempt to identify the product of the restorer gene, $R f-1$. These near isogenic lines have been derived from a backcross of Chinsurah Boro II x Taichung 65 (Shinjo 1975, 1984). They are [normal]rf-1/rf-1 Taichung 65 as a maintainer line (BTB), $\mathrm{B}_{21} \mathrm{~F}_{1}[m s-b o] r f-1 / r f-1$ as a CMS line (BTA), and $\mathrm{B}_{12} \mathrm{~F}_{8}[m s-b o] R f-1 / R f-1$ as a restorer line (BTR).

Total RNA was isolated using Isogen (Nippongene, Japan) from anthers at the microspore stage, because $R f-1$ gene is expected to be expressed in microspores (Shinjo 1975, 1984). Differential display combined with reverse transcription-polymerase chain reaction analysis (DDRT-PCR, Liang and Pardee 1993) was carried out between RNA from BTR and that from BTB.

We obtained three cDNA fragments specific to BTR in PCR reactions out of 8 primer combinations. The cDNA fragments were used to identify restriction fragment length polymorphism (RFLP) between BTR, BTB, and BTA. Only one cDNA, i.e., DD2-3, yielded a BTR-specific RFLP (Fig. 1A). Therefore, this clone was selected for further characterization.

Sequencing analysis revealed that the $1305 \mathrm{bp}$ DD2-3 clone was amplified by a PCR primer, 5'ATGCTGGGGA-3'. Full-length cDNA was ob-
(A)

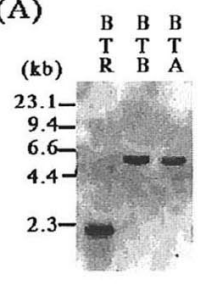

(B)

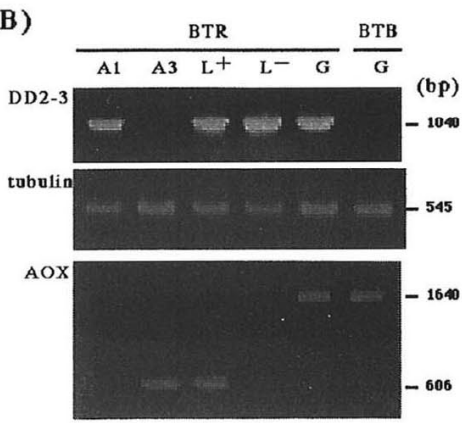

Fig. 1 Detection of DD2-3 gene and transcripts. (A) RFLP of DD2-3 gene in CMS isogenic line $[m s-b o] r f-1 / r f-1$ (BTA), maintainer line [nor$m a l] r f-1 / r f-1$ (BTB), and restorer line $\left[m s^{-}\right.$ bo]Rf-1/Rf-1 (BTR). Genomic DNA was digested with Hind III and the blot was probed with a DDRT-PCR fragment of DD2-3.

(B) RT-PCR to detect transcripts of DD2-3, tubulin and alternative oxidase (AOX). RNA was isolated from anthers at the microspore stage (A1), mature anthers (A3), leaves treated with salicylic acid $\left(\mathrm{L}^{+}\right)$and untreated leaves $\left(\mathrm{L}^{-}\right)$of BTR. The PCR product obtained using genomic DNA as a template is also shown (G) in BTR and BTB. Twenty micrograms of total RNA was used for each RT-PCR, and 100 ng of genomic DNA was used for genomic PCR. PCR was carried out for 30 cycles for $1 \mathrm{~min}$ at $94^{\circ} \mathrm{C}, 2 \mathrm{~min}$ at $55^{\circ} \mathrm{C}$, and $2 \mathrm{~min}$ at $72^{\circ} \mathrm{C}$.

tained by $5^{\prime}-$ RACE and $3^{\prime}-$ RACE $\left(5^{\prime}-\right.$ Full RACE 


\section{(A)}

LLKKLAG LEESLAS VPPESGES MDEDLYP VGGTSTND VGGPDDYV

\section{(B )}

DD2 - 3 VLPIVGGPGMGKTYLARFLFNDDRVKQAF QVRHWVHLSPHF I 2 C1 1 VVPIVGMGGLGKTTLAKAVYNDESVKNHFDLKAWFCVSEAY

(C)

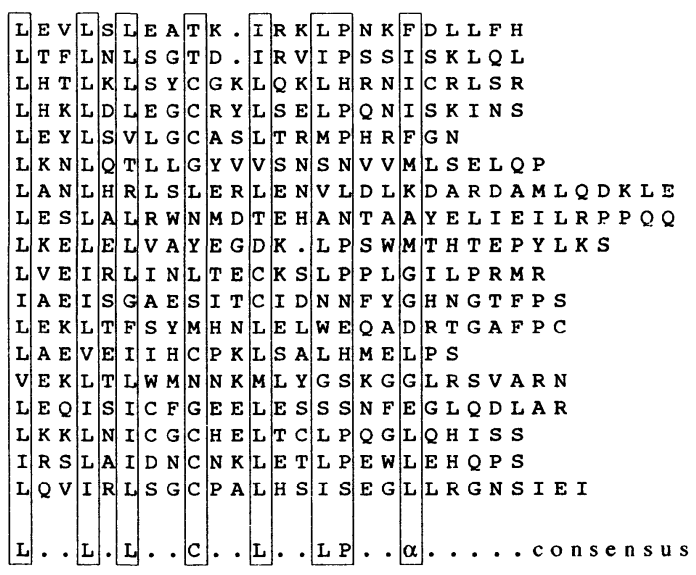

Fig. 2 A part of the amino acid sequence of DD2-3. (A) leucine-zipper like structure from residues 120 to 161 . Leucine, valine and methionine appears at every seventh position as indicated by underlines. (B) Comparison of the putative NBS of DD2- 3 (residues 194 - 234) and that of I2C1 (residues 196 - 236). Colons and dots indicate identical and similar residues, respectively.

(C) Alignment of LRR of DD2-3 from residues 577 to 1030 . The consensus sequence of the alignment is shown below. Dots represent gaps introduced to maintain alignment, and $\alpha$ represents an aliphatic residue.

Core Set and 3'-Full RACE Core Set, Takara, Japan). At least three independent PCR clones were sequenced. Finally, cDNA, 3489 bp in length was obtained. As shown in Fig. 2, the predicted protein having 1,101 amino acids contains sequences similar to those of the nucleotide binding site (NBS) and leucine-rich repeats (LRR), which is characteristic of the NBS-LRR class of plant disease-resistant genes such as I2C-1(Ori et al. 1997), RPM1(Grant et al. 1995), and PRF (Salmeron et al. 1996). However it is different from the NBS-LRR class genes recently isolated from rice (Leister et al. 1998, Yoshimura et al. 1998). In addition, a protein encoded by DD2-3 cDNA contains a leucine-zipper structure at the $\mathrm{N}$-terminus (Fig. 2).

We designed DD2-3 specific primers, 5'-GATCTATCTGAGGGTGTCAG-3' and 5'-CTGAGGACTTCAAGATGTCG-3', which could amplify a $1.04 \mathrm{kbp}$ fragment in the cDNA and genomic DNA of BTR. No such PCR product was observed in case of BTB (Fig. 1B). These primers were used to detect transcripts of DD2-3 in BTR. The transcripts were detected in the anthers at the microspore stage, but not in the mature anthers (Fig. 1B). The transcripts were also detected in leaves independent of the treatment with salicylic acid, which is known to induce pathogen-related genes (Nishizawa and Hibi 1991). We used primers (5'GCTTCCCCACTGATATCTTC-3' and 5' TGATGCAAATCCTCGGCAGTAG-3') to detect a gene for alternative oxidase with an intron (Abe $e t$ al. 1997) as a positive control for salicylic acid induction, and primers (5'-TGGTCGGATTCGCCCCGCTG-3' and 5'-TTACATGTCGTCAGCCTCCT-3') for beta-tubulin gene as a constitutive control.

The DD2-3 gene was mapped by RFLP analysis and integrated in the high-resolution rice RFLP map (Harushima et al. 1998) and was shown to be tightly linked to the RFLP marker G376 at 101.1 $\mathrm{cM}$ on the chromosome 11. In contrast, the $R f-1$ locus has been determined to lie on the chromosome 10 (Shinjo 1975, 1984). Therefore, the DD2-3 gene is not linked to the $R f-1$ gene and is likely to be derived from a chromosomal fragment of a cytoplasm donor, Chinsurah Boro II, which remained in the restorer line BTR independent of the $R f-1$ gene, even though backcross was carried out twelve times.

In conclusion, the DD2-3 gene was not linked to the restorer gene. We have, however, demonstrated that it is expressed in the immature anthers and leaves of the restorer line. The expression of the NBS-LRR class of gene in immature anthers is another point of interests and the functional significance of the DD2-3 gene in anthers should be elucidated by further study.

\section{Acknowledgment}

The authors wish to thank Dr. Masahiro Yano, Rice Genome Research Program, National Institute of Agrobiological Resources, Japan for the mapping of the DD2-3 gene.

\section{References}

Abe, F., Kitashiba, H., Kishitani, S., Toriyama, K., 1997. Isolation of a cDNA clone encoding the alternative oxidase expressed in rice anthers. Sex. Plant Reprod., 10: $374-375$.

Grant, M.R., Laurence, G., Straube, E., Ashfield, T., Lewald, J., Sattler, A., Innes, R.W., Dangl, J., 1995. Structure of the Arabidopsis RPM1 gene enabling dual specificity disease resistance. Science, 269: 843-846.

Harushima, Y., Yano, M., Shomura, A., Sato, M., Shimano, T., Kuboki, Y., Yamamoto, T., Lin, S.Y., Antonio, B.A., Parco, A., Kajiya, H., Huang, N., Yamamoto, K., 
Nagamura, Y., Kurata, N., Khush, G.S., Sasaki, T., 1998. A high-density rice genetic linkage map with 2275 markers using a single $F_{2}$ population. Genetics, 148: $479-494$.

Leister, D., Kurth, J., Laurie, D.A., Yano, M., Sasaki, T., Devos, K., Graner, A., Schulze-Lefert, P., 1998. Rapid reorganization of resistance gene homologues in cereal genomes. Proc. Natl. Acad. Sci. USA, 95: 370-375.

Liang, P., Pardee, A.B., 1993. Differential display of eukaryotic messenger RNA by means of the polymerase chain reaction. Science, 257: 967-971.

Nishizawa, Y., Hibi, T., 1991. Rice chitinase gene: cDNA and stress-induced expression. Plant Sci., 76: 211218.

Ori, N., Eshed, Y., Paran, I., Presting, G., Aviv, D., Tanksley, S., Zamir, D., Fluhr, R., 1997. The I2C family from the wilt disease resistance locus $I 2$ belongs to the nucleotide binding, leucine-rich repeat subfamily of plant resistance genes. Plant Cell, 9: 521-532.
Salmeron, J.M., Oldroyd, G.E.D., Rommens, C.M.T., Scofield, S.R., Kim, H.S., Lavelle, D.T., Dahlbeck, D., Staskawicz, B.J., 1996. Tomato $\operatorname{Prf}$ is a member of the leucine-rich repeat class of plant disease resistance genes and lies embedded within the pto kinase gene cluster. Cell, 86: 123-133.

Shinjo, C., 1975. Genetical studies of cytoplasmic male sterility and fertility restoration in rice, Oryza sativa L. Sci. Bull. Coll. Agric. Univ. Ryukyus., 22: 1- 57.

Shinjo, C., 1984. Cytoplasmic male sterility and fertility restoration in rice having Genome A. In: Tsunoda, S., Takahashi, N. (Eds.): Biology of Rice. 321-338. Japan Science Societies, Tokyo/ Elsevier Press, Amsterdam.

Yoshimura, S., Yamanouchi, U., Katayose, Y., Toki, S., Wang, Z.X., Kono, I., Kurata, N., Yano, M., Iwata, N., Sasaki, T. 1998., Expression of Xa1, a bacterial blightresistance gene in rice, is induced by bacterial inoculation. Proc. Natl. Acad. Sci. USA, 95: 1663-1668. 